\title{
Using Statistical Analysis of an Acceleration-Based Bridge Weigh-In-Motion System for Damage Detection
}

\author{
Eugene OBrien ${ }^{1}\left(\mathbb{D}\right.$, Muhammad Arslan Khan ${ }^{1, * \mathbb{D}}$, Daniel Patrick McCrum ${ }^{1}(\mathbb{C}$ \\ and Aleš Žnidarič ${ }^{2}$ \\ 1 School of Civil Engineering, University College Dublin, D04 V1W8 Belfield, Ireland; \\ eugene.obrien@ucd.ie (E.O.); daniel.mccrum@ucd.ie (D.P.M.) \\ 2 Slovenian National Building and Civil Engineering Institute (ZAG), 1000 Ljubljana, Slovenia; \\ ales.znidaric@zag.si \\ * Correspondence: muhmmad.khan@ucdconnect.ie; Tel.: +353-7163-239
}

Received: 9 December 2019; Accepted: 14 January 2020; Published: 17 January 2020

\begin{abstract}
This paper develops a novel method of bridge damage detection using statistical analysis of data from an acceleration-based bridge weigh-in-motion (BWIM) system. Bridge dynamic analysis using a vehicle-bridge interaction model is carried out to obtain bridge accelerations, and the BWIM concept is applied to infer the vehicle axle weights. A large volume of traffic data tends to remain consistent (e.g., most frequent gross vehicle weight (GVW) of 3-axle trucks); therefore, the statistical properties of inferred vehicle weights are used to develop a bridge damage detection technique. Global change of bridge stiffness due to a change in the elastic modulus of concrete is used as a proxy of bridge damage. This approach has the advantage of overcoming the variability in acceleration signals due to the wide variety of source excitations/vehicles-data from a large number of different vehicles can be easily combined in the form of inferred vehicle weight. One year of experimental data from a short-span reinforced concrete bridge in Slovenia is used to assess the effectiveness of the new approach. Although the acceleration-based BWIM system is inaccurate for finding vehicle axle-weights, it is found to be effective in detecting damage using statistical analysis. It is shown through simulation as well as by experimental analysis that a significant change in the statistical properties of the inferred BWIM data results from changes in the bridge condition.
\end{abstract}

Keywords: bridge health monitoring; BWIM; structure dynamics; damage detection; vehicle-bridge interaction; SHM

\section{Introduction}

Bridge structures are amongst the most critical components of transport infrastructure. Similar to other structures, they deteriorate over their lifetimes due to aging, environmental conditions and traffic loading [1-3]. Structurally deficient bridges may be unsafe, and continuous monitoring of bridges is desirable in such situations. In the United States, $9.1 \%$ of the total number of bridges in 2016 were found to be structurally deficient and to require substantial investment and improvements to operate [4]. Therefore, an effective method of bridge damage detection is important to detect damage quickly when it occurs. In recent years, many methods of bridge damage detection have been proposed for road authorities to maintain an acceptable level of bridge safety [5]. These methods are classified using levels of damage identification. For example, Level I damage detection methods identify the presence of damage in the structure, Level II methods identify the location of damage, Level III methods quantify the extent of damage and Level IV methods predict the remaining service life of the structure [6]. Visual inspection is the most frequently used method, but it can be expensive, time-consuming and disruptive to traffic. Stochino et al. used a combination of visual inspection and 
non-destructive testing of materials to calculate a condition rating number (CRN) and hence develop a low-cost SHM system [7]. This concept is tested on a set of real bridges to calculate the CRN and assess the damage category of each bridge based on their visual inspection and assumed material strength properties. Although the method is simple, low-cost and fast, it is less sensitive to small changes in temperature and environmental conditions around the bridge.

Direct instrumentation is an approach to structure health monitoring (SHM) in which sensors (typically accelerometers or strain transducers) are installed on the bridge. The most popular systems are based on analysing bridge natural frequencies and modes extracted from sensors installed at various locations on the bridge [8]. However, there tends to be a slight change in the bridge natural frequencies, which are used to identify bridge damage (Level I) for a significant change in the bridge condition. Cantero et al. proposed a bridge damage detection method (Level I) using a strain-based weigh-in-motion (WIM) system which is sensitive to damage only if the location of damage is near the sensor [9]. For that reason, arrays of distributed sensors are required to identify damage.

Indirect monitoring is an alternative approach, where an instrumented vehicle crossing the bridge is used to infer information about its condition [10]. The most recent indirect monitoring systems are able to detect changes in bridge damping [10] and natural frequency [11,12] using vehicle accelerations. Zhang et al. estimated mode shape squares from vehicle accelerations and proposed a new damage index of the bridge [13]. Malekjafarian et al. extracted full bridge mode shapes using vehicle accelerations in segments of the bridge [14]. While the indirect SHM methods with instrumented vehicles are easy to operate and are cost effective, the damage indicators are very sensitive to the vehicle velocity, changes in road profile and environmental conditions [10].

In some of the latest SHM systems, unmanned aerial vehicles (UAVs) have measured bridge displacements and mode shapes using vision-based techniques [15]. Although the use of UAVs is convenient, low cost and can access remote parts of the bridge, the visual measurements may not yet be accurate enough for short-span bridges, where the bridge deflections in response to passing heavy vehicles are typically less than one millimetre. Another type of SHM system involves the use of machine learning algorithms that process indirect measurements from the vehicle [16] or direct bridge response measurements $[17,18]$ to identify structural abnormalities. In these systems, the measurements from the healthy bridge condition are analysed to build and train a model [16]. Yi et al. employed a multi-stage energy-based method for damage assessment that uses a wavelet packet transform and an artificial neural network (ANN) to detect local damages in steel frame structures [17]. A benchmark structure of the American Society of Civil Engineers (ASCE) was tested in a laboratory to validate the model. Jin et al. proposed an extended Kalman filter-based ANN model for SHM that estimates the weights in a regression neural network to detect bridge damage under severe temperature changes [18]. They trained the neural network using one-year of measured bridge accelerations and temperature data using a real bridge to test the concept. Although the machine learning models have shown promising results, they require a great deal of bridge data to train the model effectively and are demanding of computational resources due to the large number of unknown parameters.

Bridge weigh-in-motion (BWIM) is a technique for finding the gross vehicle and axle weights of trucks crossing a bridge, using a measured bridge $[19,20]$. Any variation in the bridge structural condition (stiffness) changes its behaviour and manifests itself in the form of changes in inferred BWIM weights. Therefore, there have been some studies on the use of the BWIM system for bridge damage detection [9].

The BWIM technique was first proposed by Moses, who found the vehicle axle weights by minimising the sum of squared differences between the measured and calculated responses of a bridge [19]. The gross vehicle weights (GVWs) were then calculated by summing the inferred axle weights. BWIM systems generally consist of two sets of sensors: one for axle detection [21] and a second to obtain the responses used to infer the axle weights [22]. Traditional BWIM systems use strain responses which are measured by strain gauges, strain transducers or fibre Bragg grating (FBG) sensors $[9,23]$. However, a BWIM system that uses strain measurements directly is not suitable for 
bridge monitoring. Many bridges are statically determinate (single span simply supported), and the bending moment is unaffected by stiffness. As a result, strain responses only change if the sensor is located at (or very close to) the damaged point. If the bridge is damaged at another location, strain is not affected, and any strain-based BWIM system becomes ineffective at detecting damage. Ojio et al. [24] used bridge deflection instead of strain, measured without using any sensors attached to the bridge, and developed a contactless bridge weigh-in-motion (cBWIM) system which has reasonably good accuracy for GVWs [25].

Sekiya et al. proposed a portable BWIM system that uses acceleration rather than strain as the bridge response. It integrates the acceleration signals twice to estimate the displacements and uses this for the BWIM analysis [26]. In this integration process, the influence of initial conditions is significant, and this adversely affects the accuracy. Specifically, pre-existing vibrations may be present and may contaminate the calculations. To overcome this problem, large numbers of accelerometers are needed and, even then, accuracy is relatively poor.

The effect temperature has on stiffness of concrete structures is a well-known phenomenon that influences all health monitoring techniques and needs to be understood for a perfect structural health monitoring system $[27,28]$. Concrete bridges are always subject to change in stiffness due to temperature change as it affects the modulus of elasticity and compressive strength of concrete. Higher temperature levels cause linear degradation in the modulus of elasticity and compressive strength of concrete, which implies that any increase in temperature decreases the global stiffness of the bridge. Increases in temperature affect the chemical bonds of concrete paste, causing breaking and disintegration of concrete products and reducing the elastic modulus of concrete [26]. There is a consensus in the literature that the relationship between the concrete modulus of elasticity and temperature is linear [27,28], but there is no consensus on the slope of the linearity. Similar to concrete, glass material experiences mechanical degradation due to long-term changes in humidity and temperature, which affect the dynamic parameters of the structure [29]. Bedon illustrated the effect of changing ambient conditions on bridge frequencies using a glass suspension footbridge [29]. Bedon et al. used a glass walkway structure to demonstrate the correlation between the bridge frequencies and vibration comfort level [30].

In recent years, the application of smart sensors has gained interest among many researchers. Chen et al. summarized the literature on smart SHM techniques for long-term monitoring of long-span arch bridges [31]. Bridge strain and acceleration responses have been applied to a monitoring system [31] commonly used to monitor traffic loading and extract modal parameters and bridge frequencies to detect damage, respectively. Chen et al. also conducted a case study with the application of five integrated subsystems for a smart SHM and assessed the advantages and disadvantages of various signal processing techniques on bridge acceleration and strain responses [31]. They monitored a long-span bridge in China for changing environmental and traffic load effects using an extensive layout of fibre optic sensors and environmental sensors to develop an effective long-term SHM system. Although the systems discussed in [31] have been found to be reasonably effective, they require a high number of sensors on the bridge which makes the installation time-consuming and expensive.

In this paper, a novel smart approach to bridge damage detection, using a statistical analysis of acceleration-based BWIM results, is proposed which not only identifies damage (Level I) but also quantifies the extent of damage in the bridge. The acceleration responses are used directly to infer the GVWs. This means that the proposed SHM system is able to monitor traffic loading as well as bridge condition. A statistical analysis of the inferred GVWs allows the detection of damage. This approach is shown to work with only one acceleration measurement, which can be measured using a portable accelerometer, and information on axle configuration. Therefore, it can eliminate the requirement for many sensors to be installed on the bridge. This will not only make the SHM system cost effective but will also reduce the time to setup the system on the bridge. It is known that bridge accelerations are sensitive to damage, i.e., loss of bridge stiffness [32,33]. Hence, a system that can reduce the number of sensors will decrease the cost as well as time of installation. A statistical approach is applied to the results to develop an effective method of bridge damage detection. To test the concept, 
a one-dimensional vehicle model is simulated on a simply supported beam with a class ' $A$ ' road profile [34] to obtain the bridge acceleration responses. Global stiffness loss due to a change in the bridge modulus of elasticity is used as bridge damage. The BWIM results are calculated for various values of vehicle parameters, and the statistical properties of the results are reviewed. Field measurements on a reinforced concrete bridge in Slovenia are used as a complementary test of the concept.

\section{Numerical Model}

\subsection{Bridge Model}

The bridge model used in this paper is a $6 \mathrm{~m}$ long simply supported rectangular beam. The finite element model of the beam contains 30 discretized beam elements having 4 degrees of freedom each for translation and rotation at each end [35]. The mechanical properties of the bridge are shown in Table 1.

Table 1. Properties of the bridge.

\begin{tabular}{ccc}
\hline Bridge Property & Notation & Value \\
\hline Total no. of degrees of freedom & $\mathrm{N}$ & 62 \\
Young's Modulus & $\mathrm{E}$ & $35 \times 10^{9} \mathrm{~N} / \mathrm{m}^{2}$ \\
2nd moment of area & $\mathrm{J}$ & $0.114 \mathrm{~m}^{4}$ \\
Mass per unit length & $\mu$ & $7000 \mathrm{~kg} / \mathrm{m}$ \\
Damping & $\xi$ & $3 \%$ \\
1st natural frequency & $\mathrm{f}_{1}$ & $32.2 \mathrm{~Hz}$ \\
Approach Length & $\mathrm{L}_{\mathrm{app}}$ & $100 \mathrm{~m}$ \\
\hline
\end{tabular}

The bridge accelerations at any location change with time depending on the vehicle position. A sampling frequency $\left(\mathrm{f}_{\mathrm{s}}\right)$ of $500 \mathrm{~Hz}$ is assumed. $\mathrm{N}_{\mathrm{b}}$ is a $\left(\mathrm{n}_{\mathrm{a}} \times \mathrm{n}_{\mathrm{s}}\right)$ location matrix created for each axle location on the bridge where $n_{s}$ is the total number of time steps and $n_{a}$ is the number of axles. A road profile, generated randomly according to the ISO standard [36], is added with a class ' $\mathrm{A}$ ' roughness to the MATLAB program [34], and an approach length is added to ensure that the vehicle degrees of freedom are in equilibrium when the vehicle arrives on the bridge [37]. Dynamic responses of the modelled beam to the moving vehicle are given by the system of equations at each time-step:

$$
\mathrm{K}_{\mathrm{b}} \mathrm{y}_{\mathrm{b}}+\mathrm{C}_{\mathrm{b}} \dot{\mathrm{y}}_{\mathrm{b}}+\mathrm{M}_{\mathrm{b}} \ddot{\mathrm{y}}_{\mathrm{b}}=\mathrm{N}_{\mathrm{b}} \mathrm{f}_{\mathrm{int}}
$$

where $K_{b}, C_{b}$ and $M_{b}$ are the $(n \times n)$ bridge stiffness, damping and mass matrices, respectively, and $\mathrm{y}_{b}, \dot{\mathrm{y}}_{\mathrm{b}}$ and $\ddot{\mathrm{y}}_{\mathrm{b}}$ are the $\left(\mathrm{n} \times \mathrm{n}_{\mathrm{s}}\right)$ vectors of bridge nodal displacements, velocities and accelerations, respectively. $f_{\text {int }}$ is the vector of the total bridge and vehicle interaction forces containing static and dynamic loads at an axle contact point. The dynamic loads are determined using the road profile and the bridge displacement under each vehicle axle.

The damage considered in this paper is a percentage loss of bridge modulus of elasticity to represent a global loss of bridge stiffness. The bridge stiffness, which is also related to the bridge damage, changes proportionally with the change in the modulus of elasticity [27]. In the numerical study in this paper, a percentage change in the concrete modulus of elasticity is used as a proxy of damage due to temperature change.

\subsection{Vehicle and System Models}

Two types of vehicle model are used in this paper. The first one is a system of a quarter-car, and the second one is a half-car crossing the bridge. A single quarter-car and two discrete quarter-cars are used to assess the feasibility of the acceleration-based BWIM system as these models are not affected by hop mass pitch rotation. The quarter-car model has 2 degrees of freedom (DOFs) which consist of sprung mass bounce translation and axle hop translation [38]. The mechanical properties of the quarter-car [39], other than its sprung mass, velocity and axle-spacing, are shown in Table 2. 
Table 2. Properties of the quarter-car.

\begin{tabular}{ccc}
\hline Quarter-Car Vehicle Property & Notation & Value \\
\hline Total degrees of freedom & $\mathrm{n}_{\mathrm{v}}$ & 2 \\
Each unsprung mass & $\mathrm{m}_{\mathrm{u}}$ & $750 \mathrm{~kg}$ \\
Each tyre stiffness & $\mathrm{K}_{\mathrm{t}}$ & $3.5 \times 10^{6} \mathrm{~N} / \mathrm{m}$ \\
Each suspension stiffness & $\mathrm{K}_{\mathrm{s}}$ & $750 \times 10^{3} \mathrm{~N} / \mathrm{m}$ \\
Each suspension damping & $\mathrm{C}_{\mathrm{s}}$ & $10^{4} \mathrm{Ns} / \mathrm{m}$ \\
\hline
\end{tabular}

A half-car vehicle model, shown in Figure 1, is a more realistic representation of a 2-axle vehicle. This model has four DOF: sprung mass bounce displacement $\left(\mathrm{y}_{\mathrm{s}, \mathrm{i}}\right)$, sprung mass pitch rotation $(\theta)$ and axle hop displacements of the two unsprung axle masses $\left(y_{u, 1}\right.$ and $\left.y_{u, 2}\right)$. The vehicle body is represented by a sprung mass $\left(\mathrm{m}_{\mathrm{s}}\right)$ and the suspension systems by the two unsprung axle masses $\left(m_{u, 1}\right.$ and $\left.m_{u, 2}\right)$. The sprung mass is connected to the axles through a combination of springs with linear stiffness $\left(\mathrm{K}_{\mathrm{s}, \mathrm{i}}\right)$ and viscous dampers with damping coefficients $\left(\mathrm{C}_{\mathrm{s}, \mathrm{i}}\right)$ and to the road surface via springs with linear stiffnesses, $\left(\mathrm{K}_{\mathrm{t}, \mathrm{i}}\right)$. Table 3 shows the mechanical properties of the model $[40,41]$. The distance of axles to centre of gravity, i.e., $\mathrm{D}_{1}$ and $\mathrm{D}_{2}$, are taken as half of the total axle spacing that is chosen randomly in each simulation run using the typical two-axle traffic data.

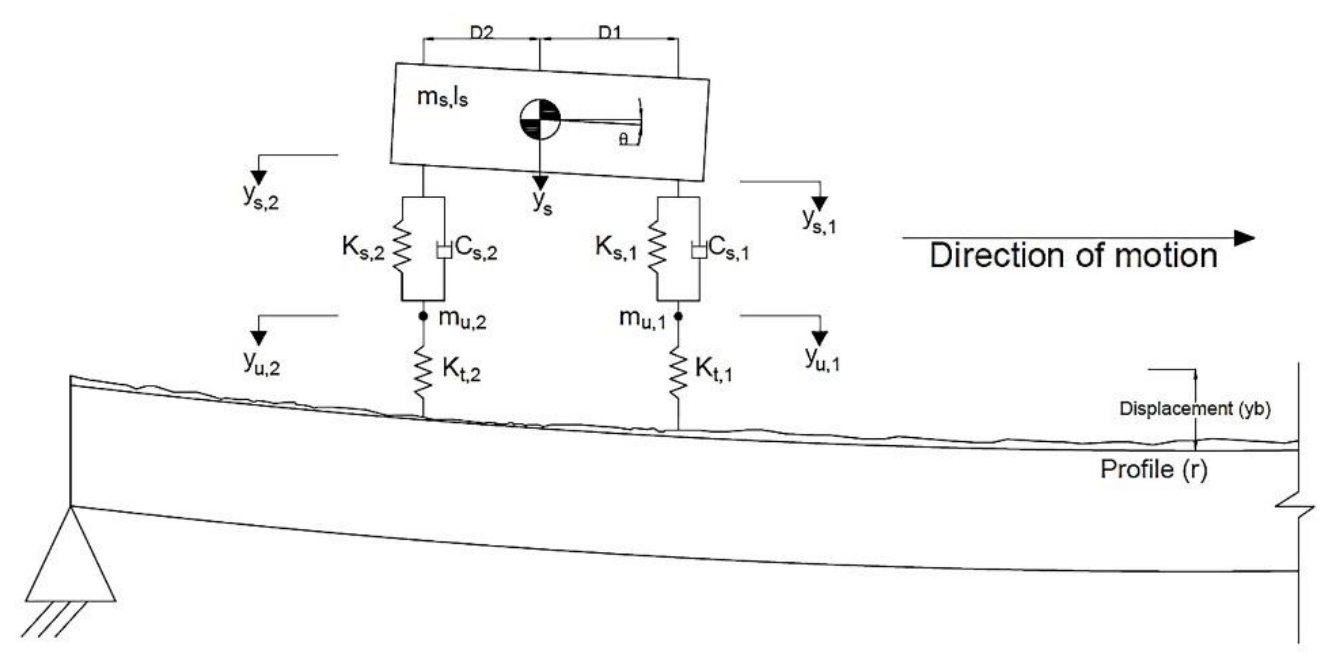

Figure 1. Section of a half-car vehicle model with general road profile on the bridge.

Table 3. Properties of the half-car model.

\begin{tabular}{ccc}
\hline Half-Car Property & Notation & Value \\
\hline Total degrees of freedom & $\mathrm{n}_{\mathrm{v}}$ & 4 \\
\hline \multirow{2}{*}{ Unsprung masses } & $\mathrm{m}_{\mathrm{u}, 1}$ & $750 \mathrm{~kg}$ \\
& $\mathrm{~m}_{\mathrm{u}, 2}$ & $1100 \mathrm{~kg}$ \\
\hline \multirow{2}{*}{ Tyre stiffness } & $\mathrm{K}_{\mathrm{t}, 1}$ & $1.75 \times 10^{6} \mathrm{~N} / \mathrm{m}$ \\
& $\mathrm{K}_{\mathrm{t}, 2}$ & $3.5 \times 10^{6} \mathrm{~N} / \mathrm{m}$ \\
\hline \multirow{2}{*}{ Suspension stiffness } & $\mathrm{K}_{\mathrm{s}, 1}$ & $0.4 \times 10^{6} \mathrm{~N} / \mathrm{m}$ \\
& $\mathrm{K}_{\mathrm{s}, 2}$ & $1 \times 10^{6} \mathrm{~N} / \mathrm{m}$ \\
\hline \multirow{2}{*}{ Suspension damping } & $\mathrm{C}_{\mathrm{s}, 1}$ & $10^{4} \mathrm{Ns} / \mathrm{m}$ \\
& $\mathrm{C}_{\mathrm{s}, 2}$ & $20 \times 10^{3} \mathrm{Ns} / \mathrm{m}$ \\
\hline
\end{tabular}

Equilibrium of forces is used to develop the equation of motion for the vehicle [33].

$$
\mathrm{K}_{\mathrm{v}} \mathrm{y}_{\mathrm{v}}+\mathrm{C}_{\mathrm{v}} \dot{\mathrm{y}}_{\mathrm{v}}+\mathrm{M}_{\mathrm{v}} \ddot{\mathrm{y}}_{\mathrm{v}}=\mathrm{f}_{\mathrm{v}}
$$


where $K_{v}, C_{v}$ and $M_{v}$ are the $\left(n_{v} \times n_{v}\right)$ stiffness, damping and mass matrices of the vehicle respectively, and $\mathrm{y}_{\mathrm{v}}, \dot{\mathrm{y}}_{\mathrm{v}}$ and $\ddot{\mathrm{y}}_{\mathrm{v}}$ are the $\left(\mathrm{n}_{\mathrm{v}} \times \mathrm{n}_{\mathrm{s}}\right)$ vectors of vehicle displacements, velocities and accelerations, respectively. The dynamic interaction forces applied to the vehicle DOFs through the road profile and bridge displacements are contained in the vector, $\mathrm{f}_{\mathrm{v}}$. The bridge and the vehicle models are coupled in a global system at each axle contact point:

$$
K_{\mathrm{g}} \mathrm{u}+\mathrm{C}_{\mathrm{g}} \dot{\mathrm{u}}+\mathrm{M}_{\mathrm{g}} \ddot{\mathrm{u}}=\mathrm{F}
$$

where $M_{g}$ and $C_{g}$ are the coupled $\left(\left(n+n_{v}\right) \times\left(n+n_{v}\right)\right)$ mass and damping matrices, respectively. $K_{g}$ is the time-varying coupled $\left(\left(n+n_{v}\right) \times\left(n+n_{v}\right)\right)$ stiffness matrix and depends on the axle location and the bridge static displacement due to vehicle loading. $\mathrm{F}$ is the force matrix of the coupled system while $\mathrm{u}, \dot{\mathrm{u}}$ and $\ddot{\mathrm{u}}$ are the $\left(\left(\mathrm{n}+\mathrm{n}_{\mathrm{v}}\right) \times \mathrm{n}_{\mathrm{s}}\right)$ vectors of displacements, velocities and accelerations of the system, respectively. Equation (3) is solved in MATLAB using the Wilson-Theta integration technique [42]. The Wilson-Theta value $(\theta)$ used in this method is 1.420815 for unconditional stability in the integration process.

\section{Statistical Approach Based on the Acceleration-Based BWIM System}

\subsection{Feasibility of the Concept}

The idea of using the bridge acceleration response for a BWIM system was first proposed by Sekiya et al. [26]. They derived the bridge displacements by integrating the acceleration responses twice and used the derived signals in the conventional BWIM algorithm [26]. In this paper, the bridge acceleration signals are used directly in the BWIM algorithm.

To simulate the acceleration response, the vehicle-bridge dynamic interaction model is programmed in MATLAB using a quarter-car vehicle and the bridge model. Displacement, velocity and acceleration at mid-span on the bridge are calculated. This location is chosen as it shows the maximum amplitude of response. The influence line response, by definition, is the bridge acceleration due to a unit single-axle load passing over the bridge and is required for the calibration of the BWIM system. The BWIM algorithm [19] uses a comparison of the calculated and measured bridge responses. The calculated response is found by summing the products of each axle weight and the influence line ordinate corresponding to its location; see Equation (4). This assumes the principles of scaling: the acceleration response to an axle with weight $\mathrm{nW}$ is $\mathrm{n}$ times the acceleration response to an axle with weight $\mathrm{W}$ and superposition: the acceleration response to a multi-axle vehicle is the sum of the responses to its individual axles. The calculated response for scan $\mathrm{i}$ is:

$$
\mathrm{R}_{\mathrm{bi}}^{\mathrm{T}}=\sum_{\mathrm{j}=1}^{\mathrm{n}_{\mathrm{a}}} \mathrm{W}_{\mathrm{j}} \mathrm{I}\left(\mathrm{x}_{\mathrm{i}}-\mathrm{d}_{\mathrm{j}}\right)
$$

where $W_{j}$ is the weight of axle $j, I(x)$ is the influence line ordinate at distance $x$ of unit-load from the start of bridge, $x_{i}$ is the location of the first axle at scan $i, d_{j}$ is the distance of axle $j$ from the first axle $\left(d_{1}=0\right)$ and na is the number of axles.

Acceleration responses can be used effectively for BWIM if the relationship between the signal amplitude and axle weight is linear or near to linear. This issue is explored by simulating the passage of a single quarter-car over the bridge with masses ranging from 5 to $30 \mathrm{t}$. Accelerations on the bridge are calculated and plotted for a constant vehicle velocity of $80 \mathrm{~km} / \mathrm{h}$. Using Monte Carlo simulation, the vehicle mechanical properties are chosen randomly for each simulation run, assuming normal distribution with standard deviations of $20 \%$. To begin with, the bridge initial conditions are kept at zero acceleration (static) in the model to represent ideal conditions, and a scanning frequency of $500 \mathrm{~Hz}$ is assumed. All the acceleration responses are plotted in the time domain. The amplitude of the first positive peak, which has the highest positive amplitude, is considered for the comparison. Figure 2 shows the bridge acceleration responses for different quarter-car masses ( $5 \mathrm{t}$ to $30 \mathrm{t}$ ) using class ' $\mathrm{A}$ ' road profile. 


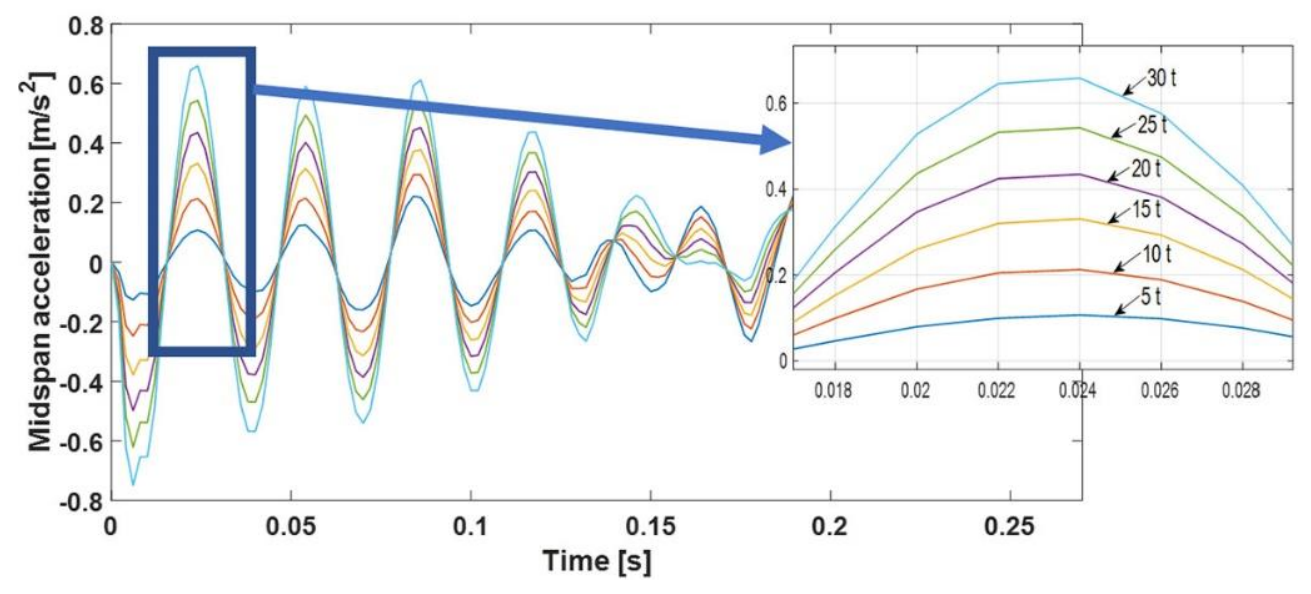

Figure 2. Bridge mid-span first-peak acceleration responses for single quarter-cars with different masses (the same road profile is used in each run of the general road profile).

The first positive peak amplitudes, normalised with respect to the $5 \mathrm{t}$ axle value, are repeated for three different bridge profiles and plotted against axle mass in Figure 3. The best fits of the plots in Figure 3 show that the amplitudes follow a reasonably linear trend for each road profile which suggests that the bridge accelerations are scalable given that there is a constant road profile. The slopes of these fits are related to accuracy of the BWIM system. Ideally for an accurate BWIM system, the slope of the fit should be 1 [43]. As it can be seen from Figure 3, slope of the fits less than 1 suggests that the acceleration-based BWIM system will underestimate the inferred weights. However, because of the slope is constant for each given road profile, the underestimation will be constant.

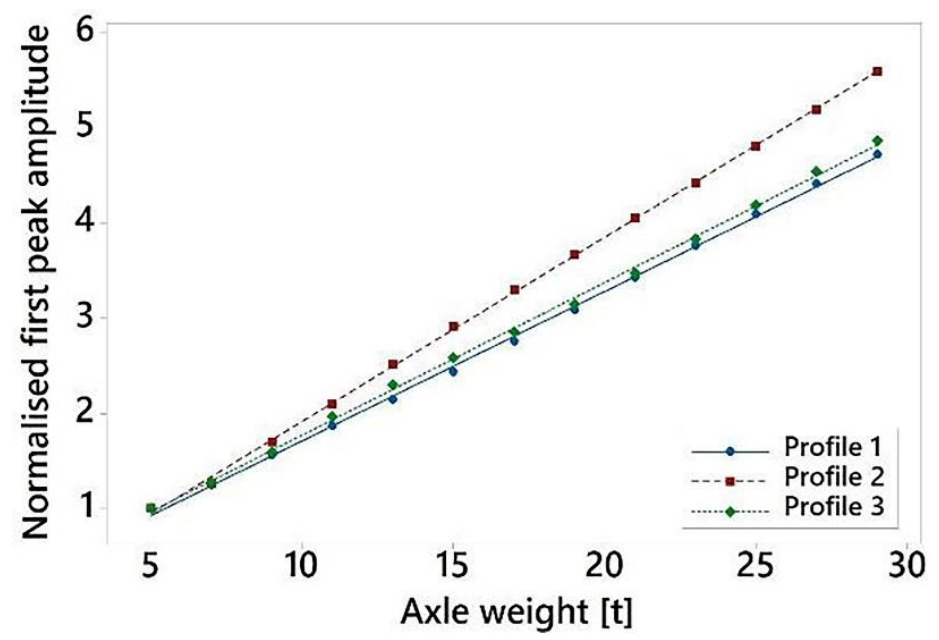

Figure 3. Relationship between axle mass and normalised 1st peak amplitude for 3 different profiles.

To test the principle of superposition, the acceleration response to two quarter-cars with $5 \mathrm{t}$ axles at $4 \mathrm{~m}$ spacing and the sum of two individual acceleration responses to individual $5 \mathrm{t}$ axles with a velocity of $80 \mathrm{~km} / \mathrm{h}$ are plotted in Figure 4. It can be seen that the sum of the individual axle responses matches very well with the response to the two axles together (superposition). Figures 3 and 4 suggest the feasibility of the acceleration-based BWIM system and indicate the effect of the road profile on the inaccuracy of the BWIM system. 


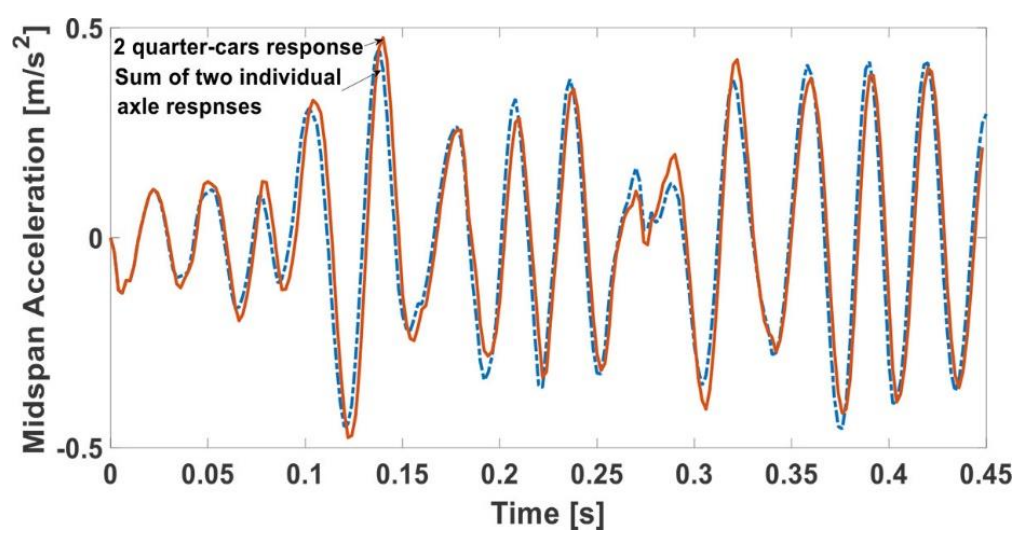

Figure 4. Bridge acceleration response to a two quarter-car vehicle and sum of the individual axle responses using the class ' $\mathrm{A}$ ' road profile.

\subsection{The BWIM Analysis Using the Half-Car Vehicle Model}

The acceleration-based BWIM system analysis is carried out using the half-car vehicle model. The bridge midspan acceleration responses for a half-car at $4 \mathrm{~m}$ axle spacing at a constant velocity of 80 $\mathrm{km} / \mathrm{h}$ and using 1 st and 2nd axle weights of 9 and $11 \mathrm{t}$, respectively, are simulated using first a smooth profile, then a class ' $A$ ' road profile. A 'calculated' bridge acceleration response is found for each simulated 'measured' acceleration response using the BWIM equations and the bridge influence line response. The simulated 'measured' and the 'calculated' bridge accelerations are shown in Figure 5a,b, using smooth profile and class ' $\mathrm{A}$ ' road [27], respectively. To simulate realistic bridge conditions, pre-existing bridge vibration is assumed on arrival of the vehicle on the bridge.

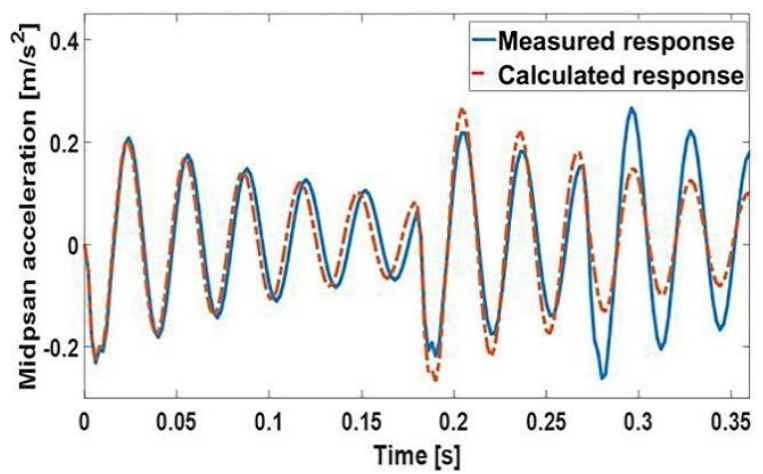

(a)

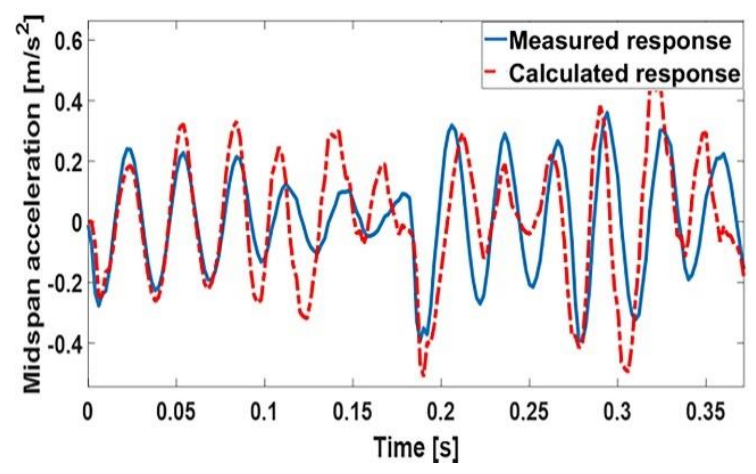

(b)

Figure 5. Mid-span 'simulated measured' and corresponding 'calculated' bridge acceleration responses using: (a) smooth profile; (b) class 'A' road profile.

During many repetitions of this exercise, simulated 'measured' and 'calculated' responses were seen to be consistently similar, although some bias is present when using a road profile, as mentioned in the section above. The BWIM algorithm is tested using the half-car vehicle model with smooth and class 'A' road profile. Moses' algorithm, illustrated in Equations (5) and (6) for a 2-axle vehicle, is based on the minimization of the sum of squared differences between the 'measured' and the 'calculated' responses [19]. The axle weights are inferred by setting the partial derivatives of the sum of squared differences to zero, as shown in Equation (6). This process results in a system of linear equations in terms of the unknown axle weights, $\mathrm{W}_{\mathrm{j}}$.

$$
\begin{gathered}
E=\sum_{i=1}^{n_{s}}\left(R_{i}^{m}-\left(W_{1} I\left(x_{i}\right)+W_{1} I\left(x_{i}-d_{2}\right)\right)\right)^{2} \\
\frac{\partial E}{\partial W_{j}}=0 ; j=1,2
\end{gathered}
$$


where $R_{i}^{m}$ is the measured bridge acceleration response for scan $i$, and $n_{s}$ is the total number of scans. The accuracy of the acceleration-based BWIM system is found by comparing the actual gross weights used to generate the accelerations with the corresponding inferred values.

Because of the consistent biasness between the 'measured' and the 'calculated' responses, the accuracy of individual vehicle weights is poor. Therefore, a statistical approach to the acceleration-based BWIM system is considered in this paper. The acceleration responses to three sets of 500 half-car vehicles are used to test the acceleration-based BWIM system under healthy bridge conditions and the results are plotted in the form of histograms in Figure $6 \mathrm{a}, \mathrm{b}$ using a smooth profile and a class ' $A$ ' road, respectively. The axle weights, velocities and axle spacings of the half-car vehicles are chosen randomly, using Monte Carlo simulation, assuming normal distributions with means and standard deviations of typical two-axle traffic data. In this section, initial free-vibration of the bridge is generated using the acceleration response to an earlier passing two quarter-car vehicle with randomly chosen vehicle properties. A single random profile of class ' $\mathrm{A}$ ' is used for the simulations. It can be seen in Figure $6 \mathrm{a}$ that the inferred weights are fairly accurate and consistent when a smooth road profile is used in the analysis and the average of the inferred GVW accuracies for each set are $-5.9 \%$, $-5.8 \%$ and $-6 \%$, respectively. In Figure $6 \mathrm{~b}$, it can be seen that the acceleration-based BWIM system underestimates the axle weights quite significantly but this inaccuracy is very consistent. The averages of the 500 inferred GVW accuracies of the BWIM system for each set in Figure $6 \mathrm{~b}$ with the half-car vehicle model are $-61.5 \%,-61.8 \%$ and $-61.7 \%$, respectively. The road profile has a significant influence on the accuracy of the acceleration-based BWIM. Therefore, the acceleration-based BWIM system is not accurate; however, importantly, it is very consistent. It is this consistency we will use to detect damage, not the accuracy of the axle weights.

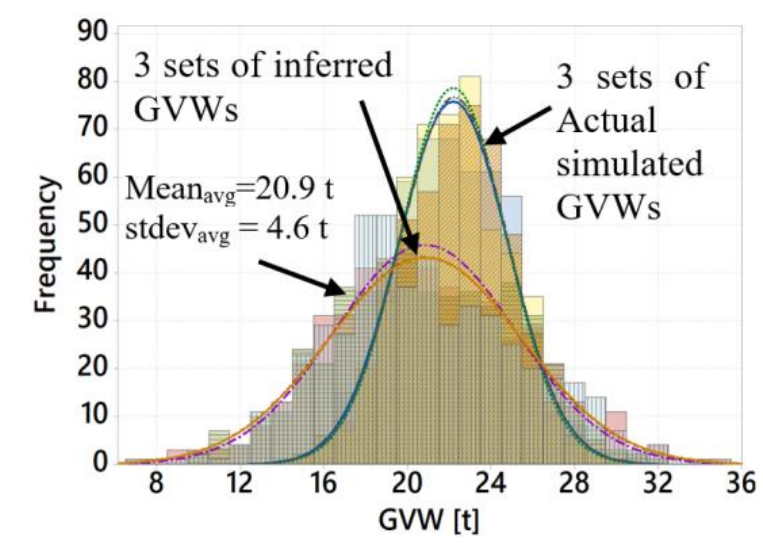

(a)

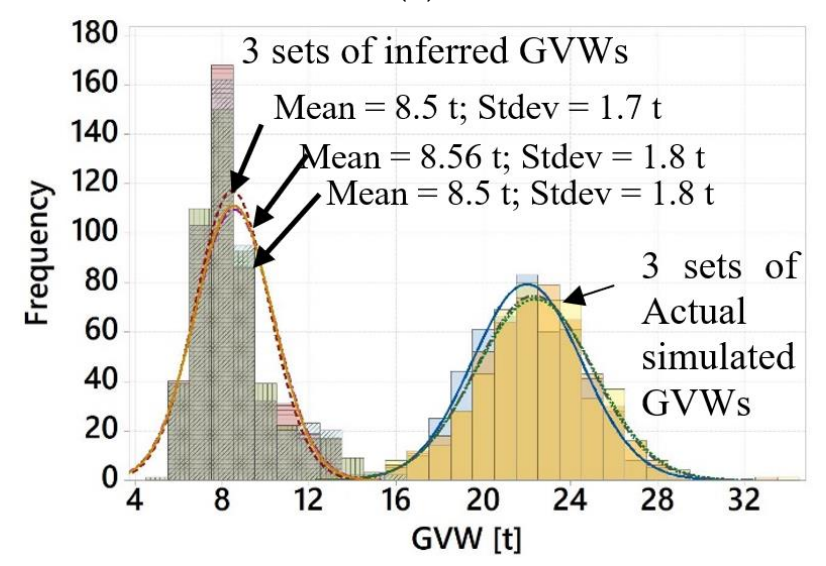

(b)

Figure 6. Histograms of actual simulated GVWs and inferred GVWs for the case of a healthy bridge with 500 half-car vehicles using: (a) smooth profile; (b) class ' $\mathrm{A}$ ' road profile. 


\section{Damage Detection Using the Statistical Approach}

The aim of this paper is to detect bridge damage using statistical analysis of acceleration-based BWIM results. As the results of inferred GVWs are repeatable (consistent estimates of axle weights), there is a potential of the BWIM system to detect any change in bridge condition since acceleration is sensitive to damage. Damage is represented here as a global loss in bridge stiffness. Since the change in global stiffness affects the bridge accelerations of all types of bridges [44], the proposed method could be expanded to bridges made of different materials. The simulated bridge with various damage conditions and the half-car vehicle model are tested numerically, and the potential of the statistical approach for bridge health monitoring is assessed. A statistical approach is applied, comparing the mean inferred GVWs. Figure 7 illustrates a schematic diagram of the methodology for bridge damage detection using a statistical approach applied to the acceleration-based BWIM system data.

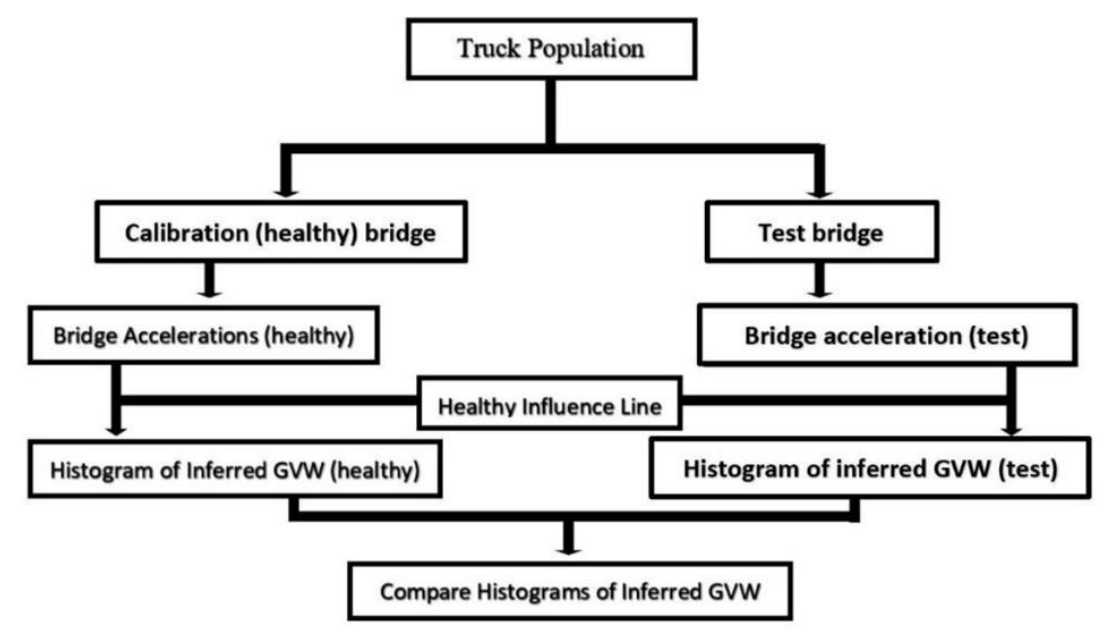

Figure 7. Schematic diagram of the methodology of bridge damage detection using the acceleration-based BWIM system.

It is seen in Figure 6a that the acceleration-based BWIM system underestimates the axle weights and is statistically biased. However, this inaccuracy is consistent, and therefore, it can be used as a baseline for detecting any change in the bridge condition. As the accelerations are sensitive to bridge damage, the statistical properties of the inferred GVWs change when the bridge is damaged. Global loss of stiffness is used as a proxy of damage. Loss of stiffness in a concrete bridge generally occurs due to change in concrete modulus of elasticity [27]. This change in bridge condition affects the bridge acceleration response, and hence affects the accuracy of the acceleration-based BWIM system. Figure 8 shows the effect of bridge damage on the mid-span acceleration response to a half-car vehicle using one class ' $\mathrm{A}$ ' road profile. The velocity of the vehicles in Figure 8 is kept constant at $80 \mathrm{~km} / \mathrm{h}$.

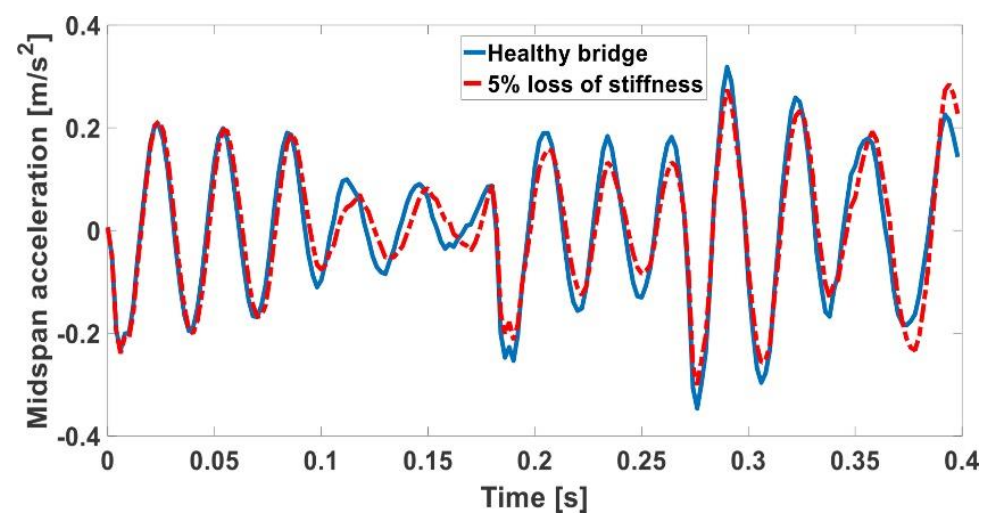

Figure 8. Effect of bridge damage in the mid-span bridge acceleration using the class 'A' road profile. 
Due to damage, the acceleration-based BWIM system malfunctions as it uses the 'calculated' response (influence line) for the healthy bridge. The gross weights inferred by the BWIM system are presented in Figure 9 for 500 trucks using the half-car vehicle model. The relative axle weights, velocities, axle spacings and pre-existing bridge vibrations are chosen randomly for the trucks which are simulated on the bridge with a class ' $\mathrm{A}$ ' profile with different percentage losses of stiffness. The percentage loss of stiffness ranges from $1 \%$ loss (low) to $10 \%$ loss (severe). It is acknowledged that $10 \%$ loss of stiffness is a significant change in bridge temperature; however, the higher loss percentages are shown to demonstrate the concept.

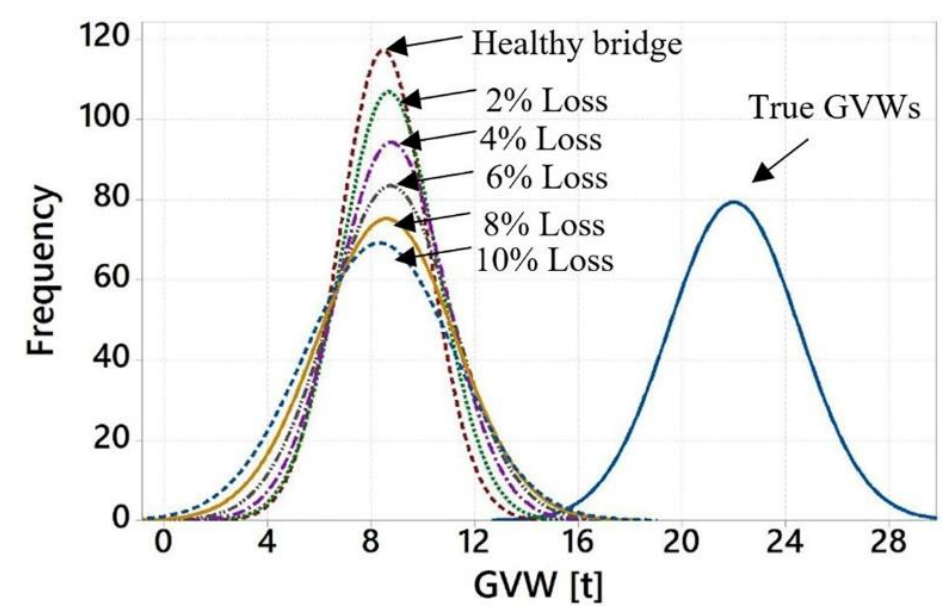

Figure 9. Normal distribution curves fitted to inferred GVWs using a half-car model using the class ' $A$ ' road profile with different percentage losses of stiffness.

As can be seen in Figure 9, the acceleration-based BWIM results demonstrate observable variation in the statistical properties when there is global loss of bridge stiffness. The variations of the means and standard deviations of the inferred GVWs with loss of stiffness are calculated. The relationship between the mean inferred GVWs and percentage loss of stiffness is found to be non-linear, but the standard deviation shows a significant and roughly linear increase with increase in the percentage stiffness loss (about 17.5\% increase for 3\% increase in stiffness loss and a coefficient of determination (R-squared) value of 99.6\%) (see Figure 10a). The sensitivity of the standard deviation to loss of stiffness is considerably greater than first natural frequency, for example, as illustrated in Figure 10b. For each percentage loss of stiffness, 1st bridge natural frequency is calculated using a fast Fourier transform of the bridge (forced) accelerations due to passing trucks. The vehicle axle weights and velocities are chosen randomly for each run. Figure 10b shows an almost linear negative slope with an R-squared value of $96.7 \%$. It can be seen that the bridge frequency decreases by about $1.2 \%$ for a $3 \%$ increase in the percentage stiffness loss. Therefore, the standard deviation of the inferred GVW is proposed here as an indicator of the loss of stiffness of the bridge. 


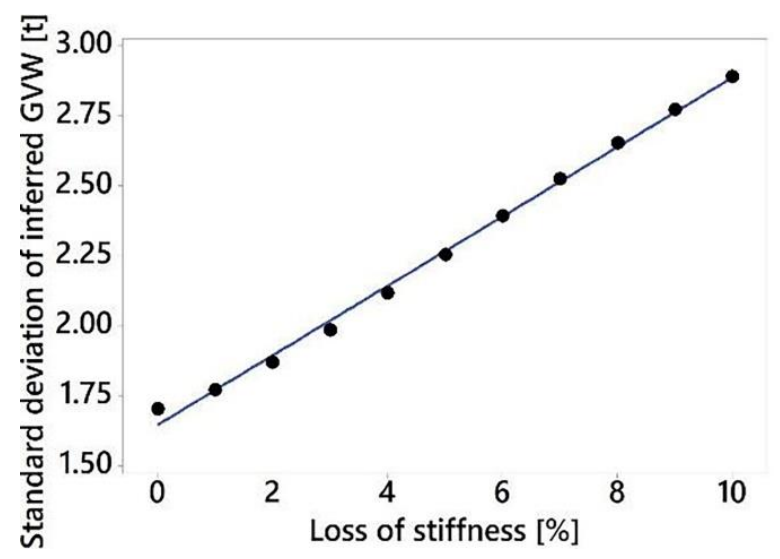

(a)

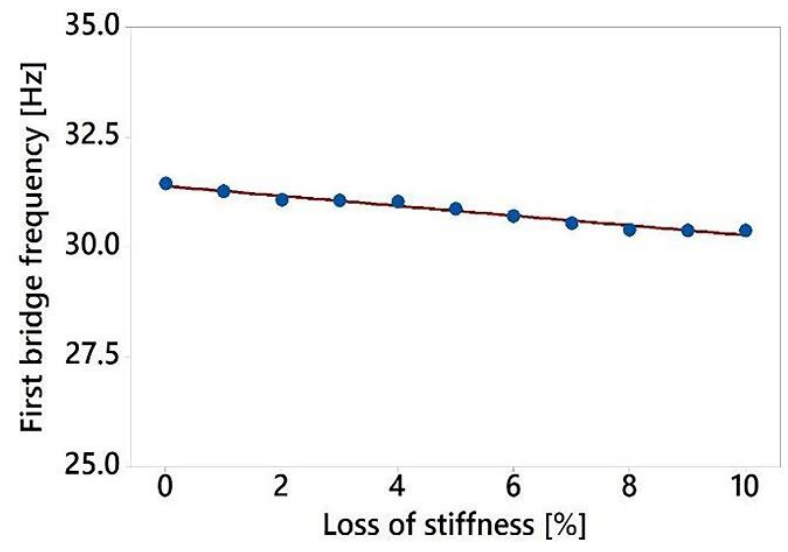

(b)

Figure 10. Change in damage indicators with the percentage loss of bridge stiffness: (a) standard deviation of inferred GVWs; (b) mean 1st bridge natural frequency.

\section{Field Tests}

The statistical approach of the proposed bridge health monitoring technique is tested on a healthy concrete slab culvert to assess the repeatability of results under field conditions. In the field analysis, the global change in stiffness (due to temperature change) is studied to investigate the change in statistical properties of BWIM data. The Šentvid bridge (see Figure 11), used for the field testing, is a $6 \mathrm{~m}$ long frame/culvert carrying two lanes of traffic and is located in the north of Ljubljana, Slovenia.

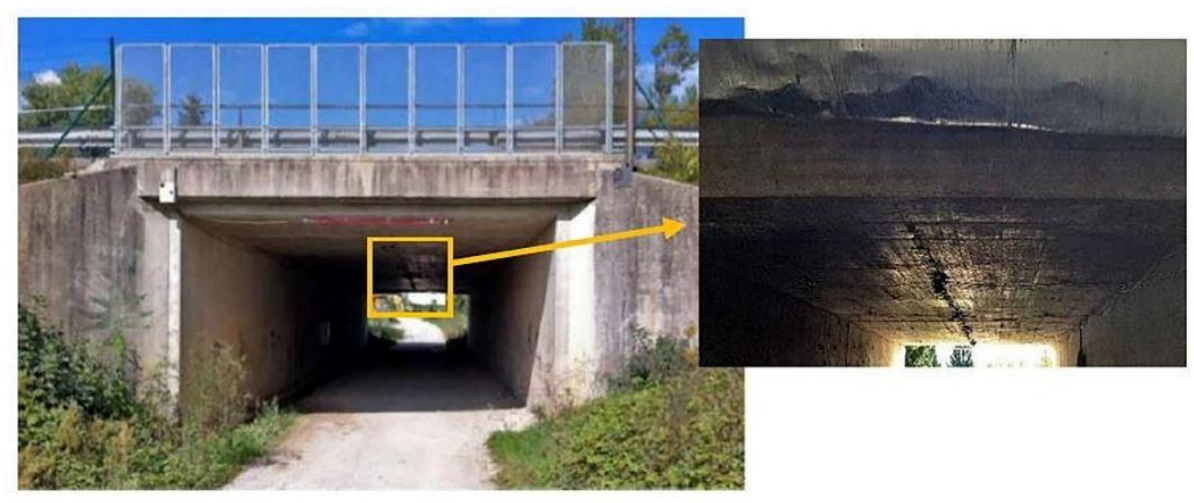

Figure 11. The Šentvid bridge in Slovenia. 
Each culvert structure is instrumented with a bridge weigh-in-motion system consisting of four free-of-axle-detector (FAD) transducers [21] and 12 weighing strain transducers which are widely used for a typical BWIM system. Figure 12 shows a plan layout of the transducers on the Šentvid bridge with dimensions in the International System of Units. The FAD transducers (7-8 and 15-16) are located near the quarter points of each culvert and are used for vehicle axle detection and to find the spacing between axles. The weighing strain transducers (1-6 and 9-14) are mounted mid-span of the $6 \mathrm{~m}$ long structure [45]. The sampling frequency of all sensors is $512 \mathrm{~Hz}$.

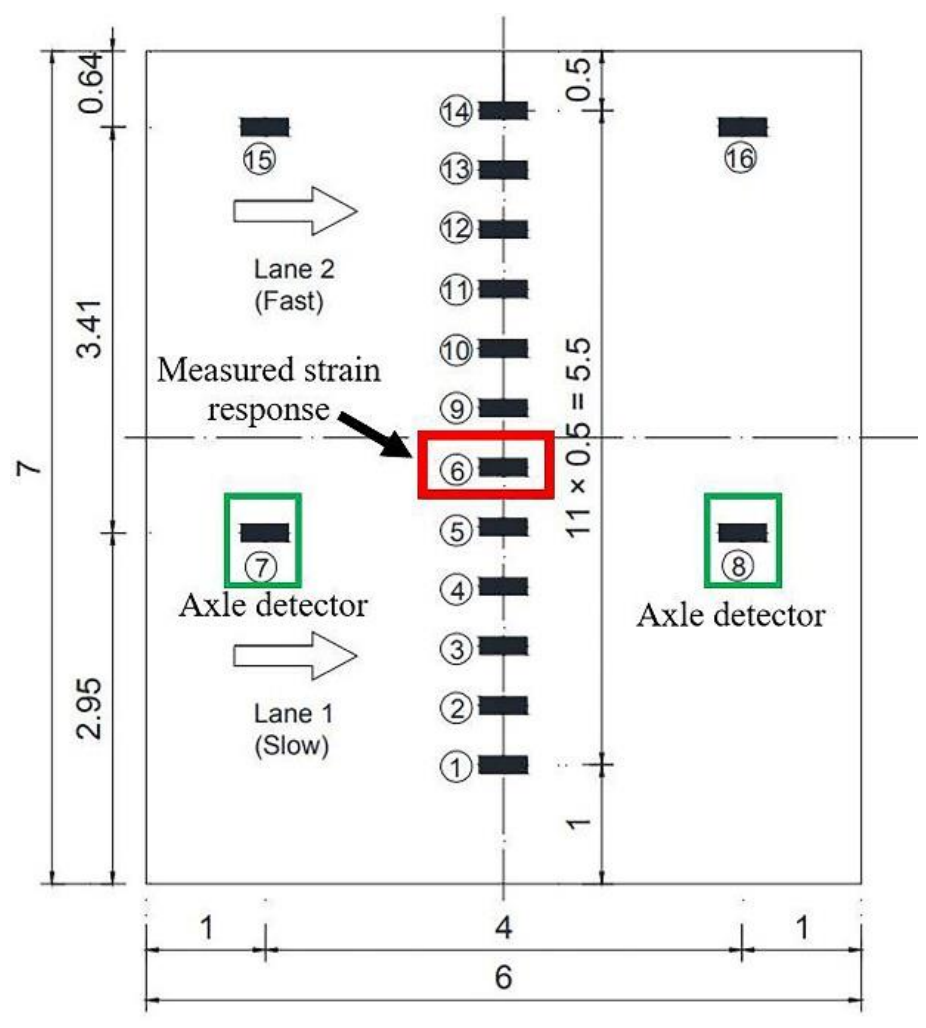

Figure 12. Plan layout of the transducers on the Šentvid bridge (dimensions in $\mathrm{m}$ ).

The acceleration-based BWIM can be applied to accelerometers or existing strain-based systems. Strain-based WIM (SiWIM) [43] is more common as the accelerometer WIM is still in early development. For the field tests, one year of data of passing trucks with axle-weights calculated from the SiWIM system is used. The mid-span strain responses of the bridge are used to approximate the acceleration responses as the difference of strain differences. It should be noted that these derived accelerations are oriented horizontally (longitudinally) rather than vertically, as would normally be measured using an accelerometer. For the remainder of the paper, acceleration response means derived accelerations from the SiWIM.

The strain response at a sensor location 6 which is under one of the wheel tracks of the trucks traveling in the slow lane of the bridge is used to derive the accelerations in this way. Figure 13a shows the strain response to a typical 5-axle truck. The peaks on the left side correspond to the passage of the first two axles while the peak on the right corresponds to the tridem axle group. The derived second derivative of the strains is shown in Figure 13b. 


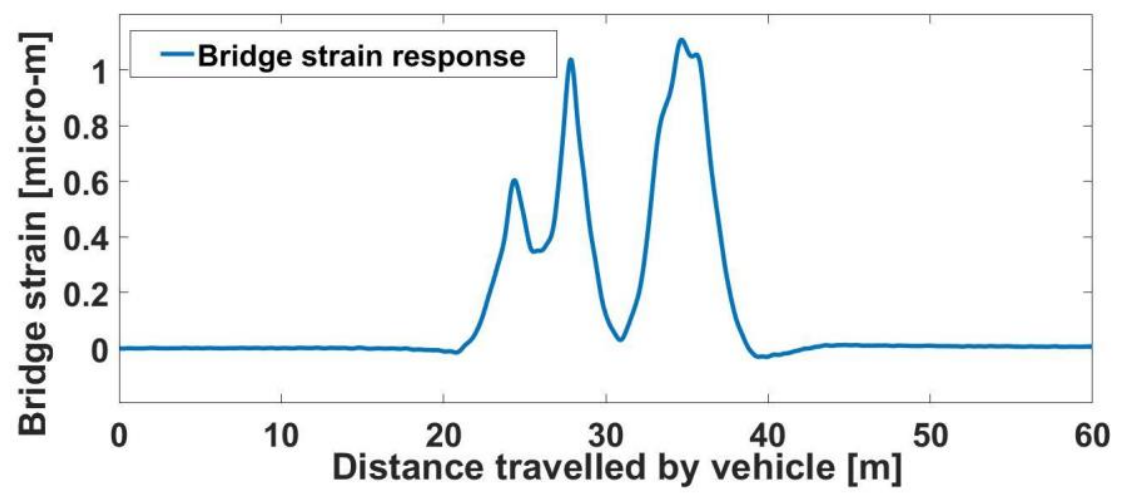

(a)

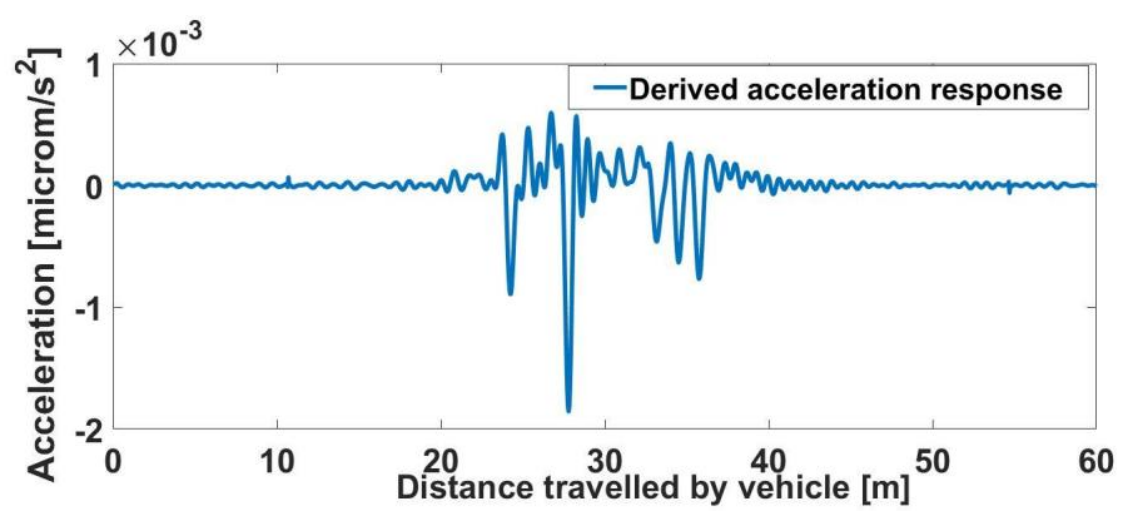

(b)

Figure 13. Measured response of the Šentvid bridge to the passage of a typical 5-axle truck: (a) Strain; (b) Derived acceleration.

\subsection{Initial Calibration for Acceleration-Based BWIM Analysis on Field Data}

A BWIM analysis is carried out using the derived acceleration responses from a year of traffic passing over the bridge. A total number of 398,445 multi-axle vehicles crossed the bridge in 2014 . As the vehicle velocity has a strong impact on the BWIM analysis [46], the velocity range of data needs to be selected. Thus, the traffic data are filtered by using only 5 -axle trucks passing within the velocity range of $23.5 \mathrm{~m} / \mathrm{s}$ to $25.5 \mathrm{~m} / \mathrm{s}$, which covers $70 \%$ of vehicle velocities, and the GVW range of $15.75 \mathrm{t}$ to $16.75 \mathrm{t}$. As a result, a dataset of 5208 trucks across the full year is used for the analysis.

To implement the BWIM concept, an influence line response is required for calibration, i.e., the acceleration response corresponding to the passage of an axle of unit weight. In this section, the influence line is back-calculated from acceleration responses similar to that shown in Figure 13b using the matrix approach described by [47]. In a process similar to that used to estimate masses [19], OBrien et al. found the influence curve which gives a least square fit of calculated to measured accelerations [47].

The acceleration responses to 10 trucks (all 5 axle trucks) passing the bridge with a constant internal bridge temperature are used to calculate 10 influence line responses, as shown in Figure 14. A sample of 10 trucks from the 5208 trucks is used as any greater sample size made little difference to the accuracy of the influence line. All 10 runs took place when the measured internal bridge temperature was $20^{\circ} \mathrm{C}$, to keep the bridge environmental conditions consistent. The influence line response for each truck passage is adjusted by shifting the phase, i.e., aligning the highest peak points in the response. Finally, the influence line used for the analysis is taken as the mean of the curves. It is shown in Figure 14 as a solid black line. 


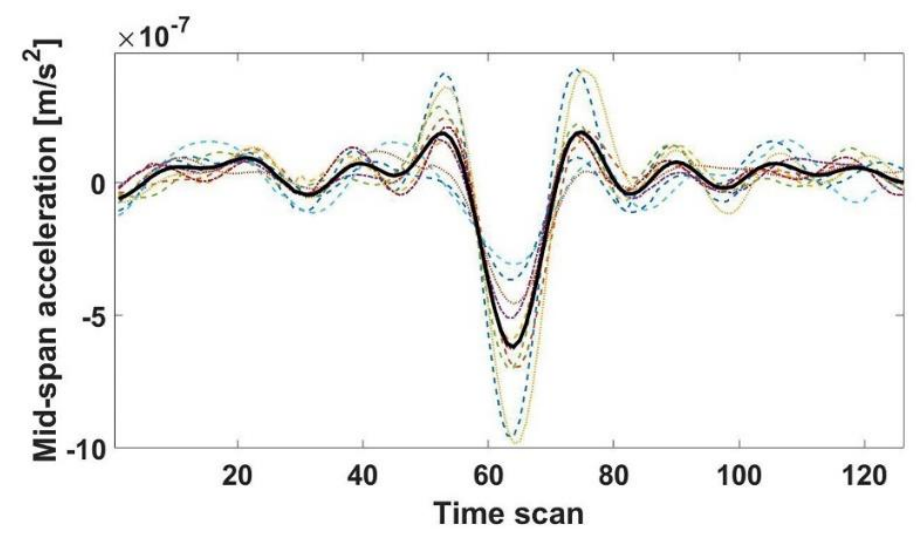

Figure 14. Bridge mid-span acceleration responses to unit-weight axle from 10 truck responses and the mean influence line response at $20^{\circ} \mathrm{C}$ temperature.

Figure 15. shows the typical measured acceleration response to a 5-axle truck and the corresponding calculated response, calculated using the mean influence line. It can be seen from Figure 15 that the calculated response matches the measured bridge response to a 5-axle truck fairly well, and the BWIM system can be developed using the mean influence line (also shown in Figure 14).

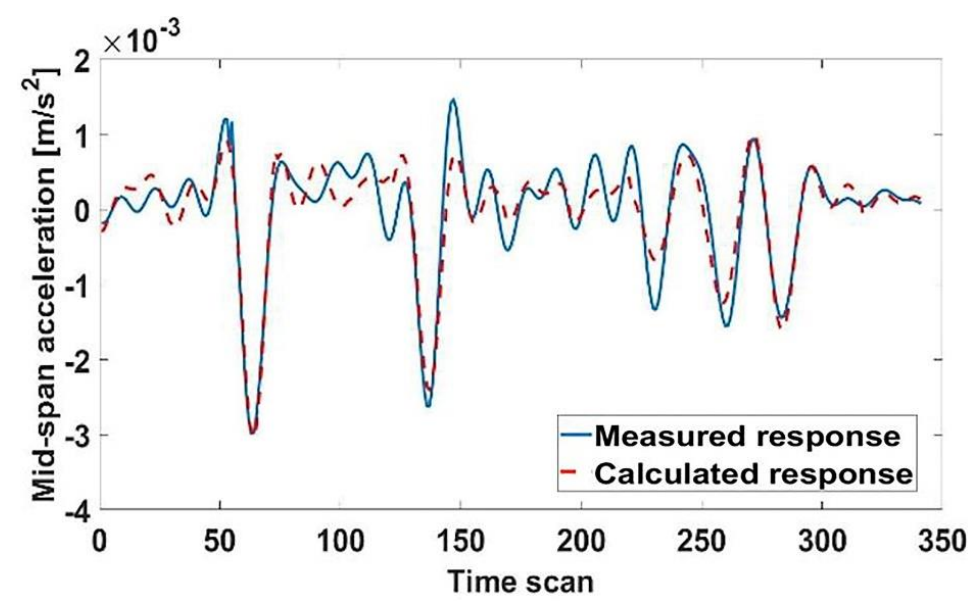

Figure 15. Typical measured bridge acceleration response to a 5-axle truck and corresponding calculated response.

\subsection{Effect of Bridge Temperature-Statistical Approach to Damage Detection}

In this section, the statistical approach for detecting a change in the bridge stiffness due to change in temperature is investigated. In this study, the internal bridge deck temperature, and its subsequent change over a year, is used as a proxy for the bridge condition; if the BWIM system responds to changes in temperature, it should also be sensitive to damage. Figure 16 shows the change in the internal temperature of the Šentvid bridge over one year. It can be seen in Figure 16 that while there is considerable variability, there is a clear difference between summer and winter temperatures. The internal temperatures are divided into 6 intervals based on equal numbers of trucks, i.e., 868 trucks per interval (i.e., $5208 \mathrm{in}$ total). This approach resulted in the intervals of $6.5-22{ }^{\circ} \mathrm{C}, 22-25{ }^{\circ} \mathrm{C}, 25-30{ }^{\circ} \mathrm{C}$, 30-33 ${ }^{\circ} \mathrm{C}, 33-35^{\circ} \mathrm{C}$ and $35-44^{\circ} \mathrm{C}$.

The BWIM analysis is carried out to compare the change in the statistical properties of the inferred steer-axle weights with the change in the mean internal bridge temperature. The influence line response from Figure 14 is used for this analysis which is calculated using a constant internal bridge temperature of $20^{\circ} \mathrm{C}$. The reason for using the steer-axle weight is the low variability of this parameter; the steer axle takes the weight of the engine and is therefore less variable than the weights of the other axles. 


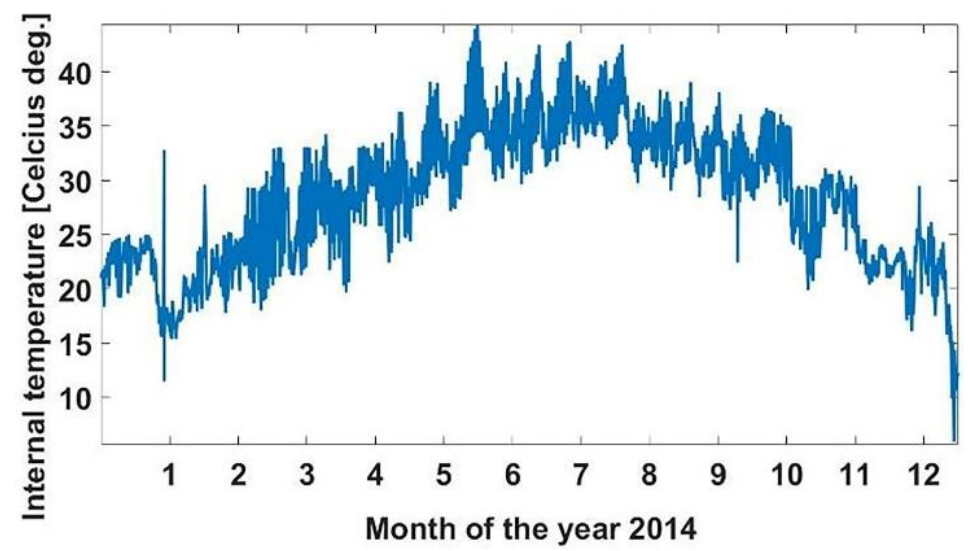

Figure 16. Measured internal temperature of the Šentvid bridge in 2014.

\subsection{Results and Discussion}

The steer-axle weights are inferred from the derived acceleration responses to 5-axle trucks crossing the Šentvid bridge. Figure 17a shows the histogram of actual steer-axle weights of trucks that crossed the bridge within the interval mean of $20^{\circ} \mathrm{C}$ and the corresponding inferred weights using the acceleration-based BWIM system.

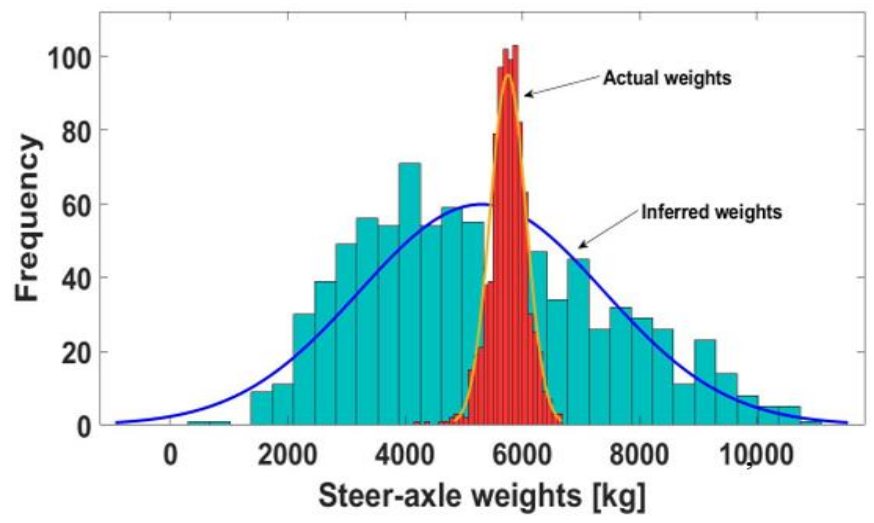

(a)

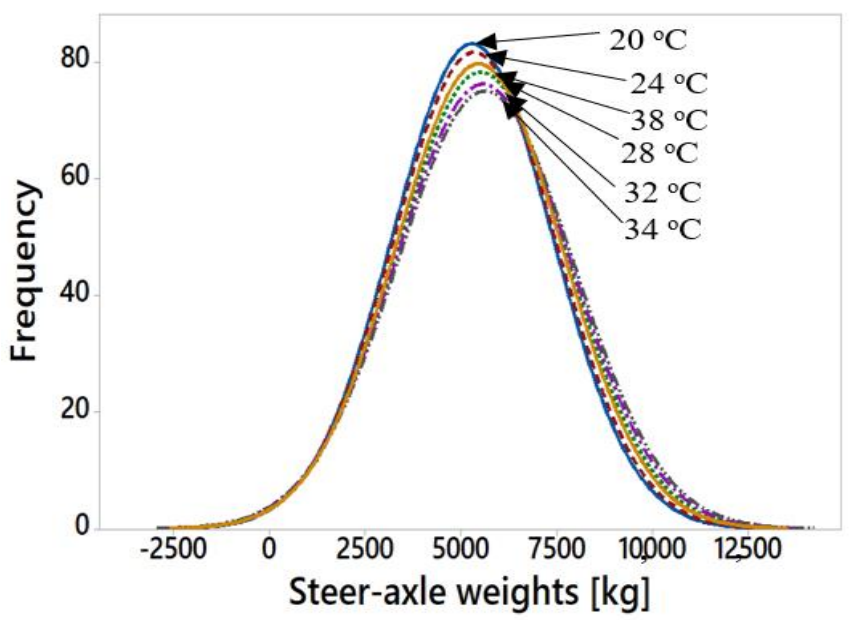

(b)

Figure 17. (a) Histograms of actual weights and the inferred steer-axle weights of trucks at $20{ }^{\circ} \mathrm{C}$ internal bridge temperature; (b) Normal distribution fits of inferred steer-axle weights with different mean internal temperatures. 
The same analysis is performed for different intervals of bridge temperature to assess the sensitivity of the statistical properties of the BWIM system to temperature. Figure $17 \mathrm{~b}$ shows the normal distribution curve fits to the histograms of inferred steer-axle weights for different temperature intervals. It can be seen in Figure $17 \mathrm{~b}$ that there are reasonable changes in both the mean and the standard deviation with temperature.

The change in the standard deviation with temperature is illustrated in Figure 18. It can be seen that the standard deviation of the inferred weights increases almost linearly with the increase in the temperature, with an R-squared value of $89.7 \%$. The standard deviation increases by about $10 \%$ due to a $10{ }^{\circ} \mathrm{C}$ increase in the bridge internal temperature which means that statistically, the acceleration-based BWIM data change with the change in bridge stiffness. Previously, the percentage change of standard deviation obtained in the numerical analysis of the one-dimension bridge beam due to global loss of stiffness is seen to be more significant (Figure 10) as compared to the percentage change in the field analysis (Figure 18). Despite the reduced performance, it is encouraging to see field evidence that this parameter, through most of the temperature range, provides a reasonable indication of a change in the bridge stiffness.

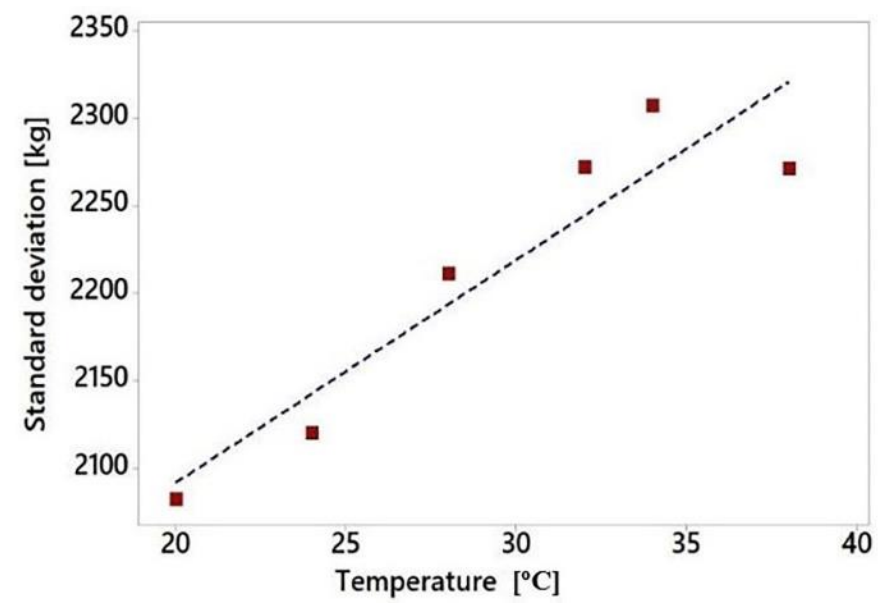

Figure 18. Inferred steer-axle weight standard deviation against the bridge internal temperature.

\section{Conclusions}

In this paper, a novel method of bridge damage detection using a statistical approach from acceleration-based BWIM data is proposed and its ability to quantify bridge damage is investigated. The bridge accelerations contain important bridge health condition information. As a result, the inferred BWIM weights are damage sensitive. Global uniform loss of bridge stiffness is used as a measure of the damage, and statistical properties of the inferred BWIM results, specifically standard deviation, are shown to be well correlated with bridge stiffness. In addition to numerical simulation, this new concept is tested in the field for global damage detection using one year of 5-axle truck data from the Šentvid bridge in Slovenia. In the field tests, the second derivative of the commonly used strain response is used as an estimate of acceleration, and temperature change is used as a proxy for damage. Both studies demonstrate that this novel approach is effective in detecting changes in bridge stiffness and is able to quantify the extent of that change. The main findings of this study are as follows:

1. In numerical analysis, the relationship between the standard deviation of inferred GVWs and bridge damage percentage is found in simulations to linearly increase. This change in the standard deviation due to bridge damage is significant, sufficiently so to be able to detect reasonably small changes in bridge condition.

2. Analysis of the field data confirms a linear and increasing relationship between the standard deviation of inferred steer-axle weights and the mean internal bridge temperatures. As temperature affects stiffness, the ability to detect temperature change is strong evidence of an ability to detect a change in the damage state. 
Bridge accelerations are damage sensitive, and the possibility of using a statistical approach for acceleration-based BWIM data for bridge damage detection has been shown to be promising using both simulations and field testing. This method can be practically applicable for long-term bridge monitoring and has a relatively low cost due to a smaller number of sensors being required than current practice methods. This method has also been shown to be applicable to SiWIM systems. An initial calibration of the bridge influence line using pre-weighed truck and a method of axle-detection is an essential element in any such installation.

Author Contributions: Conceptualization, E.O.; Formal analysis, M.A.K.; Funding acquisition, E.O.; Project administration, E.O., M.A.K. and D.P.M.; Resources, A.Ž.; Software, M.A.K.; Supervision, E.O. and D.P.M.; Visualization, E.O., M.A.K. and D.P.M.; Writing-Original draft, M.A.K.; Writing一Review \& editing, E.O., M.A.K. and D.P.M. All authors have read and agreed to the published version of the manuscript.

Funding: This research has received funding from the Science Foundation Ireland (SFI) under the US-Ireland R \& D partnership with the National Science Foundation (NSF) and Invest Northern Ireland (ID: 16/US/13277).

Conflicts of Interest: The authors declare no conflict of interest.

\section{References}

1. Lydon, M.; Taylor, S.E.; Robinson, D.; Mufti, A.; Brien, E. Recent developments in bridge weigh in motion (B-WIM). J. Civ. Struct. Health Monit. 2016, 6, 69-81. [CrossRef]

2. Yu, Y.; Cai, C.; Deng, L. State-of-the-art review on bridge weigh-in-motion technology. Adv. Struct. Eng. 2016, 19, 1514-1530. [CrossRef]

3. Richardson, J.; Jones, S.; Brown, A.; OBrien, E.; Hajializadeh, D. On the use of bridge weigh-in-motion for overweight truck enforcement. Int. J. Heavy Veh. Syst. 2014, 21, 83-104. [CrossRef]

4. U.S. Department of Transportation; Federal Highway Administration; Federal Transit Administration. 2015 Status of the Nation's Highways, Bridges and Transit: Conditions and Performance; U.S. Department of Transportation: Washington, DC, USA; Federal Highway Administration: Washington, DC, USA; Federal Transit Administration: Washington, DC, USA, 2017.

5. Hester, D.; González, A. A bridge-monitoring tool based on bridge and vehicle accelerations. Struct. Infrastruct. Eng. 2015, 11, 619-637. [CrossRef]

6. Doebling, S.W.; Farrar, C.R.; Prime, M.B. A summary review of vibration-based damage identification methods. Shock Vib. Dig. 1998, 30, 91-105. [CrossRef]

7. Stochino, F.; Fadda, M.L.; Mistretta, F. Low cost condition assessment method for existing RC bridges. Eng. Fail. Anal. 2018, 86, 56-71. [CrossRef]

8. Gomez, H.C.; Fanning, P.J.; Feng, M.Q.; Lee, S. Testing and long-term monitoring of a curved concrete box girder bridge. Eng. Struct. 2011, 33, 2861-2869. [CrossRef]

9. Cantero, D.; González, A. Bridge damage detection using weigh-in-motion technology. J. Bridge Eng. 2014, 20, 04014078. [CrossRef]

10. Malekjafarian, A.; McGetrick, P.J.; OBrien, E.J. A Review of Indirect Bridge Monitoring Using Passing Vehicles. Shock Vib. 2015, 2015, 16. [CrossRef]

11. Elhattab, A.; Uddin, N.; OBrien, E. Drive by bridge frequency identification under operational roadway speeds employing frequency independent underdamped pinning stochastic resonance (fi-upsr). Sensors 2018, 18, 4207. [CrossRef]

12. Mei, Q.; Gül, M.; Boay, M. Indirect health monitoring of bridges using Mel-frequency cepstral coefficients and principal component analysis. Mech. Syst. Signal Process. 2019, 119, 523-546. [CrossRef]

13. Zhang, Y.; Wang, L.; Xiang, Z. Damage detection by mode shape squares extracted from a passing vehicle. J. Sound Vib. 2012, 331, 291-307. [CrossRef]

14. Malekjafarian, A.; OBrien, E.J. Identification of bridge mode shapes using short time frequency domain decomposition of the responses measured in a passing vehicle. Eng. Struct. 2014, 81, 386-397. [CrossRef]

15. Spencer, B.F., Jr;; Hoskere, V.; Narazaki, Y. Advances in computer vision-based civil infrastructure inspection and monitoring. Engineering 2019, 5, 199-222. [CrossRef]

16. Malekjafarian, A.; Golpayegani, F.; Moloney, C.; Clarke, S. A machine learning approach to bridge-damage detection using responses measured on a passing vehicle. Sensors 2019, 19, 4035. [CrossRef] 
17. Yi, T.H.; Li, H.N.; Sun, H.M. Multi-stage structural damage diagnosis method based on. Smart Struct. Syst. 2013, 12, 345-361. [CrossRef]

18. Jin, C.H.; Jang, S.A.; Sun, X.R.; Li, J.C.; Christenson, R. Damage detection of a highway bridge under severe temperature changes using extended Kalman filter trained neural network. J. Civ. Struct. Health Monit. 2016, 6, 545-560. [CrossRef]

19. Moses, F. Weigh-in-motion system using instrumented bridges. J. Transp. Eng. 1979, 105, 233-249.

20. Jacob, B.; Feypell-de La Beaumelle, V. Improving truck safety: Potential of weigh-in-motion technology. Iatss Res. 2010, 34, 9-15. [CrossRef]

21. OBrien, E.J.; Znidaric, A.; Baumgärtner, W.; González, A.; McNulty, P. Weighing-In-Motion of Axles and Vehicles for Europe (WAVE) WP1. 2: Bridge WIM Systems; University College Dublin: Dublin, Ireland, 2001.

22. González, A. Development of a Bridge Weigh-in-Motion System; LAP Lambert Academic Publishing: Saarbruken, Germany, 2010.

23. Jacob, B.; O'Brien, E.J.; Newton, W. Assessment of the accuracy and classification of weigh-in-motion systems. Part 2: European specification. Int. J. Heavy Veh. Syst. 2000, 7, 153-168. [CrossRef]

24. OBrien, E.J.; Fitzgerald, P.C.; Malekjafarian, A.; Sevillano, E. Bridge damage detection using vehicle axle-force information. Eng. Struct. 2017, 153, 71-80. [CrossRef]

25. Ojio, T.; Carey, C.; OBrien, E.J.; Doherty, C.; Taylor, S.E. Contactless bridge weigh-in-motion. J. Bridge Eng. 2016, 21, 04016032. [CrossRef]

26. Sekiya, H.; Kubota, K.; Miki, C. Simplified Portable Bridge Weigh-in-Motion System Using Accelerometers. J. Bridge Eng. 2017, 23, 04017124. [CrossRef]

27. Shoukry, S.N.; William, G.W.; Downie, B.; Riad, M.Y. Effect of moisture and temperature on the mechanical properties of concrete. Constr. Build. Mater. 2011, 25, 688-696. [CrossRef]

28. Kodur, V. Properties of concrete at elevated temperatures. ISRN Civ. Eng. 2014, 2014, 15. [CrossRef]

29. Bedon, C. Diagnostic analysis and dynamic identification of a glass suspension footbridge via on-site vibration experiments and FE numerical modelling. Compos. Struct. 2019, 216, 366-378. [CrossRef]

30. Bedon, C.; Fasan, M. Reliability of Field Experiments, Analytical Methods and Pedestrian's Perception Scales for the Vibration Serviceability Assessment of an In-Service Glass Walkway. Appl. Sci. 2019, 9, 1936. [CrossRef]

31. Chen, Z.; Zhou, X.; Wang, X.; Dong, L.; Qian, Y. Deployment of a smart structural health monitoring system for long-span arch bridges: A review and a case study. Sensors 2017, 17, 2151. [CrossRef]

32. Fugate, M.L.; Sohn, H.; Farrar, C.R. Vibration-based damage detection using statistical process control. Mech. Syst. Signal Process. 2001, 15, 707-721. [CrossRef]

33. Hester, D.; González, A. A wavelet-based damage detection algorithm based on bridge acceleration response to a vehicle. Mech. Syst. Signal Process. 2012, 28, 145-166. [CrossRef]

34. Tyan, F.; Hong, Y.-F.; Tu, S.-H.; Jeng, W.S. Generation of random road profiles. J. Adv. Eng. 2009, 4, $1373-1378$.

35. González, A. Vehicle-bridge dynamic interaction using finite element modelling. In Finite Element Analysis; InTech: Terrebonne, QC, Canada, 2010; pp. 637-662.

36. ISO. Mechanical Vibration—Road Surface Profiles—Reporting of Measured Data; ISO 8608:1995; ISO: Geneva, Switzerland, 1995; Volume 1, p. 29.

37. McGetrick, P.J.; Kim, C.-W.; González, A.; Brien, E.J.O. Experimental validation of a drive-by stiffness identification method for bridge monitoring. Struct. Health Monit. 2015, 14, 317-331. [CrossRef]

38. McGetrick, P.; González, A.; O’Brien, E.J. Monitoring bridge dynamic behaviour using an instrumented two axle vehicle. In Proceedings of the Bridge \& Infrastructure Research in Ireland 2010 (BRI 10), Cork, Ireland, 2-3 September 2010.

39. Keenahan, J.; OBrien, E.J.; McGetrick, P.J.; Gonzalez, A. The use of a dynamic truck-trailer drive-by system to monitor bridge damping. Struct. Health Monit. 2014, 13, 143-157. [CrossRef]

40. Harris, N.K.; González, A.; OBrien, E.J.; McGetrick, P. Characterisation of pavement profile heights using accelerometer readings and a combinatorial optimisation technique. J. Sound Vib. 2010, 329, 497-508. [CrossRef]

41. Cebon, D. Handbook of Vehicle-Road Interaction; Swets and Zeitlinger: Lisse, The Netherlands, 1999.

42. Bathe, K.-J.; Wilson, E.L. Numerical Methods in Finite Element Analysis; Prentice-Hall: Englewood Cliffs, NJ, USA, 1976; p. 543. 
43. Žnidarič, A.; Igor, L.; Kalin, J.; Kulauzović, B. SiWIM Bridge Weigh-In-Motion Manual, 4th ed.; ZAG: Ljubljana, Slovenia, 2011.

44. Cantero, D.; Hester, D.; Brownjohn, J. Evolution of bridge frequencies and modes of vibration during truck passage. Eng. Struct. 2017, 152, 452-464. [CrossRef]

45. OBrien, E.J.; Zhang, L.; Zhao, H.; Hajializadeh, D. Probabilistic Bridge Weigh-in-Motion. Can. J. Civ. Eng. 2018, 45, 667-675. [CrossRef]

46. Yang, Y.-B.; Lin, C.; Yau, J. Extracting bridge frequencies from the dynamic response of a passing vehicle. J. Sound Vib. 2004, 272, 471-493. [CrossRef]

47. OBrien, E.J.; Quilligan, M.; Karoumi, R. Calculating an influence line from direct measurements. Bridge Eng. Proc. Inst. Civ. Eng. 2006, 159, 31-34. [CrossRef]

(C) 2020 by the authors. Licensee MDPI, Basel, Switzerland. This article is an open access article distributed under the terms and conditions of the Creative Commons Attribution (CC BY) license (http://creativecommons.org/licenses/by/4.0/). 